\title{
A Study on Evaluation of Anti-Emetics in the Prevention of Chemotherapy Induced Nausea and Vomiting in Cancer Patients in A Tertiary Care Hospital
}

\author{
Elizabeth Phoeba Paul ${ }^{*}$, Ahana Behanan', Babitha Annie Eapen 1 , Apollo James ${ }^{2}$, Sheik Haja Sherief ${ }^{2}$, \\ Mohanraj Kathirampatti Palanisamy², Thangavel Sivakumar ${ }^{3}$
}

${ }^{1}$ Pharm D Interns, Department of Pharmacy Practice, Nandha College of Pharmacy, Erode, Tamil Nadu. ${ }^{2}$ Professor, Department of Pharmacy Practice, Nandha College of Pharmacy, Erode, Tamil Nadu.

${ }^{3}$ Principal, Department of Pharmacy Practice, Nandha College of Pharmacy, Erode, Tamil Nadu.

\begin{abstract}
Background: The contemporary lifestyle has made Cancer as one of the most deadly diseases. Treatment modalities of cancer are many, while chemotherapy seems to be the most common. Though, chemotherapy subsides the disease, it has many side effects in which Chemotherapy induced Nausea and Vomiting (CINV) is frequent. This study aims to evaluate various antiemetics in the prevention of Chemotherapy induced Nausea and Vomiting in cancer patients specifically in Breast, Lung, Cervix and Head \& Neck cancers so that the rate of emesis, efficacy and comparative efficacy of different antiemetic combinations in cancer patients can be determined. Methods: A prospective observational study was carried out at a tertiary care hospital in Tamilnadu, South India between January to June, 2015 in which 241 cancer patients receiving antiemetics in their prescriptions meeting our inclusion criteria were analyzed using standard guidelines. A well designed data collection form was prepared to collect the datas. Results: It was observed from our study that the efficacy of different combination of antiemetics, mostly given as triple based regimen, relied on the treatment regimen of the particular cancer, thereby its emetogenic level and NCI-CTC grading score and it was found out that Ramosetron based triple antiemetic regimen was slightly better than Granisetron based regimen to control CINV. Conclusion: It is the need of the $\mathrm{h}$ to promote optimal antiemetic medication and ensure that cancer patient receives evidence-based, effective treatments for their health problems.
\end{abstract}

Key words: CINV, Antiemetics, Breast cancer, Lung cancer, Cervical cancer, Head \& Neck cancer.

\section{INTRODUCTION}

Still spoken of in hushed stones and feared as a worst case medical scenario, Cancer has become the modern day emperor of all maladies. Cancer is an abnormal growth of cells. There are several types of cancers and the most common ones include breast cancer, skin cancer, lung cancer, colon cancer, cervical cancers and lymphomas but symptoms vary depending on their types. ${ }^{1}$ Tobacco use is the most important risk factor for cancer causing around 20\% of global cancer deaths and around 70\% of global lung cancer deaths. ${ }^{2}$ Worldwide, Cancer figures among the leading causes of morbidity and mortality, with approximately 14 million new cases and 8.2 million cancer related deaths in 2012 according to the International Agency for Research on Cancer. ${ }^{3}$ It is said that $57 \%$ (8 million) new cancer cases, 65\% (5.3 million) cancer deaths and 48\% (15.6 million) five year prevalence of cancer cases occurred in the less developed regions of the world, if to be compared, a similar scenario in India. Globally the five most common cancers considered in both sexes were cancers of the lung $(13 \%)$, breast $(11.9 \%)$ and cervix $(3.7 \%)$. Both globally and on the Indian
DOI: 10.5530ijopp.10.1.4

Address for correspondence: Elizabeth Phoeba Paul, Pharm D Intern, Department of Pharmacy Practice, Nandha College of Pharmacy, Erode, Tamil Nadu, INDIA.

Phone no: +91 8281231295 E-mail: elizabethphoeba1892@ gmail.com

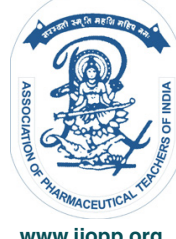

www.ijopp.org 
scene, $20 \%$ increase in breast cancer has been seen since 2008 with 1.7 million new cases diagnosed in women in $2012 .{ }^{3}$ Cancer is predominantly treated with different modalities like surgery, radiation and systemic therapies. More than half of all people diagnosed with cancer receive chemotherapy. Millions of people who have cancers respond well to chemotherapy - this approach helps treat their cancer effectively.

Though chemotherapy is beneficial, yet there are challenging adverse effects. Some of them are chemotherapy induced nausea and vomiting (CINV), alopecia, pain, cystitis, stomatitis, infections, neuropathy, cardiomyopathy, GI disturbances, diarrhea, constipation, bleeding problems, bone marrow suppression etc. Chemotherapy induced Nausea and Vomiting is mostly experienced by atleast $70 \%-80 \%$ of cancer patients which adversely affects patient's quality of life often leading to poor compliance with medications. ${ }^{4}$ Despite the use of combination of antiemetics, still patients experience nausea and vomiting during or after chemotherapy. The efficacy and potency of different antiemetics varies with patient characteristics, doses of anticancer agents and tumor location etc. The main purpose of this study was to evaluate various antiemetics in the prevention of CINV in cancer patients specifically in Breast, Lung, Cervix and Head \& Neck cancers.

\section{Our main objectives were}

To detect and determine the rate of emesis in cancer patients who are under chemotherapy.

To determine the efficacy and comparative efficacy of different combinations of Antiemetics.

\begin{tabular}{|c|c|c|}
\hline $\begin{array}{l}\mathrm{NCl}-\mathrm{CTC} \\
\text { grade }\end{array}$ & Nausea & Vomiting \\
\hline 1 & $\begin{array}{l}\text { Loss of appetite } \\
\text { without alteration in } \\
\text { eating habits }\end{array}$ & $\begin{array}{l}1-2 \text { episodes in } 24 \mathrm{~h} \\
\text { (separated by } 5 \mathrm{~min} \text { ) }\end{array}$ \\
\hline 2 & $\begin{array}{c}\text { Oral intake } \\
\text { decreased without } \\
\text { significant weight } \\
\text { loss dehydration or } \\
\text { malnutrition }\end{array}$ & $\begin{array}{l}3-5 \text { episodes in } 24 \mathrm{~h} \\
\text { (separated by } 5 \mathrm{~min} \text { ) }\end{array}$ \\
\hline 3 & $\begin{array}{c}\text { Inadequate oral } \\
\text { caloric or fluid intake } \\
\text { TPN or hospitalization } \\
\text { indicated }\end{array}$ & $\begin{array}{c}>=6 \text { episodes in } 24 \mathrm{~h} \\
\text { (separated by } 5 \mathrm{~min} \text { ) } \\
\text { tube feeding, TPN or } \\
\text { hospitalization indicated }\end{array}$ \\
\hline 4 & - & $\begin{array}{l}\text { Life threatening } \\
\text { consequences; urgent } \\
\text { intervention indicated }\end{array}$ \\
\hline 5 & - & Death \\
\hline $\begin{array}{l}\mathrm{Go}=\text { Grade } 0(1 \\
\mathrm{G}_{1}=\text { Grade } 1 \\
\mathrm{G}_{2}=\text { Grade } 2\end{array}$ & o Nausea/ No Vomiting) & $\begin{aligned} \mathrm{G}_{3} & =\text { Grade } 3 \\
\mathrm{G}_{4} & =\text { Grade } 4 \\
\mathrm{G}_{5} & =\text { Grade } 5\end{aligned}$ \\
\hline
\end{tabular}

To promote optimal antiemetic medication.

\section{MATERIALS AND METHODS}

This is a prospective, observational study carried out in a private hospital in Coimbatore district, Tamilnadu, India between January 2015 to June 2015 which includes 241 prescriptions prescribed with antiemetics. A well structured data collection form was used to collect demographical datas, diagnosis, stage of the disease, drug regimen, emetogenic level, current chemotherapy and history of past chemotherapy. Nausea and vomiting was assessed by interviewing the patients both from Daycare and Wards. These patients were reviewed during their next visit for the following chemotherapy. The grade scores of nausea and vomiting of National Cancer Institute - Common Toxicity Criteria (NCI-CTC) and National Comprehensive Cancer Network (NCCN) rating system for chemotherapeutic agents and their respective risk of acute emesis were used to measure clinical treatment outcomes. The information collected regarding all the cases were recorded in MS Excel Sheet and was analyzed.

\section{Assessment methods used}

To assess rate of nausea and vomiting, NCI - CTC grading score is used (Table 1).

\section{Levels of emetogenicity by NCCN}

Level 5 : High Emetic Risk : 90\% frequency of emesis Level 3 \& 4 : Moderate Emetic Risk : 30-90\% frequency of emesis

Level 2 : Low Emetic Risk : 10-30\% frequency of emesis

Level 1 : Minimal Emetic Risk : $<10 \%$ frequency of emesis

\section{RESULTS}

\section{Gender distribution \& Distribution of cases in each type of Cancer.}

In respect to Patient Demographics, $79 \%$ of patients were females and $21 \%$ were males and as we evaluated, it was found that females suffered more from breast and cervical cancers and in case of males, lung cancer was predominant (Table 2).

\section{Distribution of cases in each antiemetic combination}

Antiemetics are given mostly as a triple based regimen, we came across 9 different types of combinations, but we mostly received: Dexamethasone, Ramosetron, 


\begin{tabular}{|ccc|}
\hline \multicolumn{2}{|c|}{ Table 2: Distribution of cases in each Cancer types. } \\
\hline Cancer types & $\begin{array}{c}\text { Number of cases ( } \mathbf{n}= \\
\text { 241) }\end{array}$ & Percentage (\%) \\
Breast & 125 & 51.86 \\
Cervical & 44 & 18.25 \\
Head \& neck & 23 & 9.54 \\
Lung & 49 & 20.33 \\
\hline
\end{tabular}

$\begin{aligned} & \text { Table 3: Distribution of cases in each emetogenic } \\
& \text { level }\end{aligned}$
\begin{tabular}{ccc} 
Emetogenic level & $\begin{array}{c}\text { Number of cases } \\
\text { ( } \mathbf{n}=\mathbf{2 4 1})\end{array}$ & Percentage (\%) \\
\hline Level 5 & 169 & 70.12 \\
Level 3 & 40 & 16.59 \\
Level 2 & 32 & 13.27
\end{tabular}

Table 4: Distribution of cases in each antiemetic combination

$\begin{array}{ccc}\begin{array}{c}\text { Antiemetic } \\ \text { combinations }\end{array} & \begin{array}{c}\text { Number of cases } \\ (\mathbf{n}=\mathbf{2 4 1})\end{array} & \text { Percentage (\%) } \\ \text { DRD } & 154 & 63.90 \\ \text { DGD } & 75 & 31.12 \\ \text { DDA } & 1 & 0.14 \\ \text { DGDA } & 6 & 2.48 \\ \text { DGDLA } & 1 & 0.14 \\ \text { DRDLM } & 1 & 0.14 \\ \text { DROL } & 1 & 0.14 \\ \text { DDF } & 1 & 0.14 \\ \text { DDFO } & 1 & 0.14\end{array}$

Domperidone (DRD) and Dexamethasone, Granisetron, Domperidone (DGD) combinations (Table 4).

DRD:Dexamethasone, Ramosetron, Domperidone; DGD: Dexamethasone, Granisetron, Domperidone; DDA: Dexamethasone, Domperidone, Aprepitant; DGDA: Dexamethasone, Granisetron, Domperidone, Aprepitant ; DGDLA: Dexamethasone, Granisetron, Domperidone, Lorazepam, Aprepitant; DRDLM: Dexamethasone, Ramosetron, Domperidone, Lorazepam, Metoclopramide ; DROL: Dexamethasone, Ramosetron, Ondansetron, Lorazepam ; DDF: Dexamethasone, Domperidone, Fosaprepitant ; DDFO: Dexamethasone, Domperidone, Fosaprepitant, Ondansetron.

\section{Distribution of Patients in Emetogenic level 5 - Nausea \& Vomiting}

Out of 85 patients in DRD combinations, $77 \%$ of patients did not experience nausea and $80 \%$ did not experience vomiting i.e. GRADE $0,13 \%$ of patients had loss of appetite without alteration in eating habits during nausea and 10\% had 1-2 episodes of vomiting in
Table 5: Distribution of Patients in Emetogenic level 5 - Nausea \& Vomiting

Antiemetic combinations (Nausea) DRD $(n=85)$ DGD $(n=75)$

Antiemetic combinations (Vomiting)

Cases (\%)

DRD ( $n=85)$

DGD $(n=75)$

$\begin{array}{ccc}\text { G0 } & \text { G1 } & \text { G2 } \\ 77 & 13 & 9.4 \\ 53 & 37 & 9\end{array}$

Cases (\%)

G1 G2

$10 \quad 9$

$40 \quad 12$

Table 6: Distribution of Emetogenic level 3 - Nausea \& Vomiting

Antiemetic combinations (Nausea)

DRD ( $n=39)$

Cases (\%)
G0 G1

Antiemetic combinations (Vomiting) 79 Cases (\%) DRD ( $n=39)$ G0 G1 87 13

Table 7: Distribution of Emetogenic level 2 - Nausea \& Vomiting

Antiemetic combinations (Nausea)

CASES (\%) $\begin{array}{lll}\operatorname{DRD}(n=30) & \text { G0 } & \text { G1 } \\ & 90 & 10\end{array}$

Antiemetic combinations (Vomiting)

CASES (\%)

$\operatorname{DRD}(n=30)$ G0 G1 93 7

24hrs i.e. GRADE 1 and $9.4 \%$ of patients' oral intake decreased without significant weight loss dehydration or malnutrition during nausea and 9\% had 3-5 episodes of vomiting in $24 \mathrm{hrs}$ i.e GRADE 2 whereas in DGD Combinations ( 75 patients), only $53 \%$ of patients did not experience nausea and $48 \%$ did not experience vomiting. Here, we could see the patient satisfaction rate was found to be low as compared to DRD. Patients who experienced nausea were $37 \%$ and $40 \%$ experienced vomiting i.e. GRADE 1 and $9 \%$ of patients experienced nausea and $12 \%$ experienced vomiting i.e. GRADE 2 (Table 5).

\section{Distribution of Emetogenic level 3 - Nausea \& Vomiting}

There were 40 cases in this level, 39 were on DRD Combination and 1 was in DDF Combination. Out of 39 cases, in G0, $79 \%$ of patients did not experience nausea and $87 \%$ did not experience vomiting. In G1, 21\% of patients had loss of appetite without alteration in eating habits while they experienced nausea and 13\% had 1-2 episodes of vomiting in $24 \mathrm{~h}$ (Table 6).

Indian Journal of Pharmacy Practice, Vol 10, Issue 1, Jan-Mar, 2017 


\begin{tabular}{|c|c|c|c|c|c|c|c|c|}
\hline \multirow{2}{*}{$\begin{array}{l}\text { Types of } \\
\text { cancers }\end{array}$} & \multicolumn{4}{|c|}{ DRD $(n=35)$} & \multicolumn{4}{|c|}{ DGD $(n=54)$} \\
\hline & Nausea & $\%$ & Vomiting & $\%$ & Nausea & $\%$ & Vomiting & $\%$ \\
\hline \multirow{3}{*}{$\begin{array}{l}\text { Breast } \\
\text { cancer }\end{array}$} & No & 77 & V0 & 86 & No & 56 & V0 & 48 \\
\hline & N1 & 11 & V1 & 14 & N1 & 35 & V1 & 41 \\
\hline & N2 & 11 & V2 & 0 & N2 & 10 & V2 & 11 \\
\hline & \multicolumn{3}{|c|}{ DRD $(n=24)$} & & \multicolumn{4}{|c|}{ DGD (n =19) } \\
\hline \multirow{4}{*}{$\begin{array}{l}\text { Cervical } \\
\text { cancer }\end{array}$} & No & 75 & V0 & 67 & No & 53 & V0 & 42 \\
\hline & N1 & 13 & V1 & 13 & N1 & 37 & V1 & 42 \\
\hline & N2 & 13 & V2 & 21 & N2 & 11 & V2 & 16 \\
\hline & \multicolumn{4}{|c|}{ DRD $(n=18)$} & \multicolumn{4}{|c|}{$\operatorname{DGD}(n=1)$} \\
\hline \multirow{4}{*}{$\begin{array}{l}\text { Head } \\
\text { \& neck } \\
\text { cancer }\end{array}$} & No & 78 & V0 & 83 & No & 0 & V0 & 100 \\
\hline & N1 & 17 & V1 & 6 & N1 & 100 & V1 & 0 \\
\hline & N2 & 6 & V2 & 11 & N2 & 0 & V2 & 0 \\
\hline & \multicolumn{4}{|c|}{$\operatorname{DRD}(n=8)$} & \multicolumn{4}{|c|}{ DGD $(n=1)$} \\
\hline \multirow{3}{*}{$\begin{array}{l}\text { Lung } \\
\text { cancer }\end{array}$} & No & 88 & V0 & 88 & No & 0 & V0 & 100 \\
\hline & N1 & 13 & V1 & 0 & N1 & 0 & V1 & 0 \\
\hline & N2 & 0 & V2 & 13 & N2 & 100 & V2 & 0 \\
\hline
\end{tabular}

$*$ No $=$ no nausea, $* V_{0}=$ no vomiting, $* N_{1}=$ nausea with loss of appetite, $* V_{1}=1$ to 2 episodes of vomiting, $* \mathrm{~N}_{2}=$ nausea with decreased oral intake, $* \mathrm{~V}_{2}=3$ to 5 episodes of vomiting.

\begin{tabular}{|c|c|c|c|c|}
\hline \multicolumn{5}{|l|}{ Emetogenic level - 3} \\
\hline \multirow[t]{2}{*}{ Type of cancer } & \multicolumn{4}{|c|}{ DRD ( $n=39)$} \\
\hline & Nausea & $\%$ & Vomiting & $\%$ \\
\hline \multirow[t]{3}{*}{ Lung cancer } & NO & 79 & V0 & 87 \\
\hline & N1 & 21 & $\mathrm{~V} 1$ & 13 \\
\hline & N2 & 0 & V2 & 0 \\
\hline \multicolumn{5}{|l|}{ Emetogenic level - 2} \\
\hline \multirow[t]{5}{*}{ Breast cancer } & \multicolumn{4}{|c|}{ DRD $(n=30)$} \\
\hline & Nausea & $\%$ & Vomiting & $\%$ \\
\hline & NO & 90 & V0 & 93 \\
\hline & N1 & 10 & $\mathrm{~V} 1$ & 7 \\
\hline & N2 & 0 & V2 & 0 \\
\hline
\end{tabular}

$*$ No $=$ no nausea,$* V_{0}=$ no vomiting, $* \mathrm{~N}_{1}=$ nausea with loss of appetite, $* \mathrm{~V}_{1}=1$ to 2 episodes of vomiting, $* \mathrm{~N}_{2}=$ nausea with decreased oral intake, $* \mathrm{~V}_{2}=3$ to 5 episodes of vomiting.

\section{Distribution of Emetogenic level 2 - Nausea \& Vomiting}

Out of 30 patients in DRD combinations, $90 \%$ of patients did not experience nausea and 93\% did not experience vomiting i.e.G0 while $10 \%$ of patients had loss of appetite without alteration in eating habits during nausea and 7\% had 1-2 episodes of vomiting (Table 7).

Antiemetic Combinations with Aprepitant that we received were the following:

Two cases in emetogenic level 5 : DGDLA, DGDA

One case in emetogenic level $2:$ DDA
Antiemetic Combinations with Fosaprepitant that we received were:

One case in emetogenic level 2 : DDFO and

One case in emetogenic level 3 : DDF

As we received only few number of cases, comparison couldn't be done accurately to find out the best. Patients with Aprepitant combinations showed best results where $87.5 \%$ of patient did not experience nausea and $75 \%$ did not experience vomiting at all but $25 \%$ of patients experience GRADE 1 nausea and 25\% experienced GRADE 1 vomiting. 


\begin{tabular}{cccc|}
\multicolumn{4}{|c|}{ Table 10: Relation of CINV with AGE } \\
\hline Age & $\begin{array}{c}\text { Total no. of } \\
\text { cases }\end{array}$ & $\begin{array}{c}\text { Total no. } \\
\text { of cases } \\
\text { experienced } \\
\text { CINV }\end{array}$ & Percentage \\
Less than 50 & 86 & 51 & $59 \%$ \\
Greater than 50 & 155 & 84 & $54 \%$
\end{tabular}

Table 8 \& Table 9 illustrates that DRD combination works better in Breast and Cervical cancer patients in emetogenic level 5 and level 2 than DGD as the percentage of $\mathrm{N} 0$ and $\mathrm{V} 0$ is higher in $\mathrm{DRD}$, which means that number of people who didn't experience nausea and vomiting was more. In Head \& Neck cancer, DRD and DGD seems to be equally better in emetogenic level 5 whereas in Lung cancer DRD seems to be superior in emetogenic level 5 and level 3.

Chemotherapy induced Nausea and Vomiting in relation with age of a patient showed an increased risk of emesis for age less than 50 years ${ }^{[5,7]}$ and in our current study, we could find a slight increase of CINV in patients less than 50 years than in patients more than 50 years of age. (Table 10)

\section{DISCUSSION}

Chemotherapy induced Nausea and Vomiting is a challenging adverse effect experienced by atleast 70\%-80\% of cancer patients which adversely affects patient's quality of life often leading to poor compliance with medications. ${ }^{5}$ Despite the use of combination of antiemetics, still patients experience nausea and vomiting during or after chemotherapy. The efficacy and potency of different antiemetics varies with patient characteristics (both mental and physical), doses of anticancer agents and tumor location etc.

We have selected 4 types of cancers (breast, lung, cervical, head \& neck) which are being given different types of drug regimens for various stages in cancers. Chemotherapy induced Nausea and Vomiting is analysed in our study using the NCCN emetogenic level of anticancer drugs and the NCI -CTC criteria.

This prospective observational study evaluated the combination of antiemetics being use in the prevention of Chemotherapy induced Nausea and Vomiting in 241 cancer patients to detect and determine the rate of emesis and comparative efficacy of antiemetics in four different types of cancers such as breast, cervical, head $\&$ neck and lung cancers.

The most prescribed antiemetic combinations and the number of cases we received in each combination were:

1. Dexamethasone, Ramosetron, Domperidone (DRD) - 154 cases
2. Dexamethasone, Granisetron, Domperidone (DGD) - 75 cases

3. Dexamethasone, Domperidone, Aprepitant (DDA) - 1 case

4. Dexamethasone, Domperidone, Fosaprepitant, Ondansetron (DDFO) -1 case

5. Dexamethasone, Granisetron, Domperidone, Lorazepam, Aprepitant (DGDLA) - 1 case

6. Dexamethasone, Granisetron, Domperidone, Aprepitant (DGDA) - 6 cases

7. Dexamethasone, Ramosetron, Domperidone, Lorazepam, Metoclopramide (DRDLM- 1 case.

8. Dexamethasone, Ramosetron, Ondansetron, Lorazepam (DROL) - 1 case

9. Dexamethasone, Domperidone, Fosaprepitant (DDF) - 1 case.

Out of the 9 Anti-Emetic Combinations, we got the first two combinations more in number than the other 7 Anti-Emetic Combinations i.e. DRD and DGD combinations and so we could focus only on these two combinations.

Out of 241 patients enrolled in the study, 78 patients $(32.36 \%)$ were from Daycare (out patients) and 163 patients $(67.63 \%)$ from wards. Daycare patients were given mostly a triple based regimen of Dexamethasone, Granisetron and Domperidone whereas patients in wards received Dexamethasone, Ramosetron and Domperidone. Some received other combinations including Aprepitant and Fosaprepitant together with Dexamethasone and Domperidone.

The drug regimen selected by the physician for each type of cancer depends on the stage of cancer. We categorised the drug regimen into a particular emetogenic level by taking into consideration of the drug's emetogenic levels. Each drug has its own emetic risk. It can be of high emetogenic risk, moderate emetogenic risk or minimal emetogenic risk. Some patients receive single anticancer drug whereas some receive a combination of anticancer drugs. When a patient receives a combination of anticancer drugs of different emetogenic level, we select the highest level of emetogenecity.

We analysed our primary objective using the NCICTC Criteria where we graded nausea and vomiting of a patient by interacting with the patient/their family member about the present feeling and his/her condition during $24 \mathrm{~h}$ of chemotherapy. The NCCN emetogenic guidelines of oncology helped in checking out the efficacy and the comparative efficacy of antiemetics which was our second objective.

In our study nausea seems to be more severe in patients than vomiting. Evidences also prove that 
nausea has a greater impact on quality of life than vomiting in patients receiving chemotherapy. ${ }^{6} \mathrm{~A}$ study stated that nausea was the first and the most severe and vomiting as the third most severe symptom. ${ }^{?}$

According to NCI-CTC criteria there are 5 different grades but in our study we receive patients belonging to two different grades (G1, G2) and a group of patients who didn't experience neither nausea nor vomiting and we named them as G0 for the easy purpose analysis in our studies.

We evaluated the anti-emetics used in the prevention of Chemotherapy induced Nausea and Vomiting in Cancer patients in the hospital in respect to the emetogenic levels of the drug regimen being given to the patient.

The patients receiving DRD Combinations has a lesser rate of emesis than patients receiving DGD Combinations. Previous studies also reports that the long lasting efficacy of Ramosetron than Granisetron and also half-life of Ramosetron was $5.78 \pm 1.18 \mathrm{~h}$ whereas that of Granisetron was $3.14 \pm 1.20 \mathrm{~h}^{8}{ }^{8}$ Ramosetron belongs to $5-\mathrm{HT}_{3}$ receptor antagonists which is a tetrahydrobenzimidazole derivative structurally different from Granisetron and Ondansetron with more potent $5-\mathrm{HT}_{3}$ antagonizing effects., ${ }^{4}$

It has been proved in many of the articles that antiemetic combinations including Aprepitant are efficacious than those anti-emetic combinations without Aprepitant in the control of emesis because current studies support a three-drug combination of $5-\mathrm{HT}_{3}$ antagonists, a corticosteroid and an NK-1 antagonist for the prevention of nausea and vomiting after Cisplatin containing regimens ${ }^{8,10,11}$ and moderately emetogenic chemotherapy. Moreover, Aprepitant has shown its efficacy in providing a superior protection against Chemotherapy induced Nausea and Vomiting in adult patients. ${ }^{12}$

\section{CONCLUSION}

There is no doubt that the experience of Chemotherapy induced Nausea and Vomiting is intractable and powerfully aversive. Over the past decades clinical researches steadily improved control of CINV. Treatment specific and patient specific related factors affect the incidence and severity of CINV. There are anti-emetics of different classes which control CINV of different potencies and half-lives. Some control acute CINV and some delayed CINV but some can control both acute and delayed to some extent.

Our current study observed that the anti-emetic combination including Ramosetron, i.e (DRD) was found to be a better combination than the anti-emetic combi- nation which included Granisetron, i.e. (DGD) because nausea and vomiting was less in patients who took DRD anti-emetic combination than those who took DGD anti-emetic combination. Aprepitant combinations were also found to be efficacious but the main disadvantage is its cost.

It was found that, nausea was more than vomiting in patients who underwent chemotherapy. Anticipatory nausea is more common in patients.

\section{ACKNOWLEDGEMENTS}

We express our heartfelt gratitude to our professors of Department of Pharmacy Practice,friends and also thank the patients who participated in our study.

\section{REFERENCES}

1. Deshields TL, Potter P, Olsen S, Liu J, Dye L. Documenting the Symptom Experience of Cancer Patients. The Journal of Supportive Oncology. 2011;9:216-23. https://doi.org/10.1016/j.suponc.2011.06.003 ; PMid:22055891.

2. WHO Cancer Fact sheet [Internet] Feb, 2015. Available from <http://www. who.int/mediacentre/factsheets/fs297/en>

3. Saranath D, Khanna A. Biomedical Research Journal. 2014;1(1):1-5

4. Sanmukhani JJ, Pawar P, Mittal R. Ramosetron hydrochloride for the prevention of cancer chemotherapy induced nausea and vomiting: The Indian experience. South Asian Journal of Cancer. 2014.3;2:132-7.

5. Navari RM. Overview of the updated antiemetic guidelines for chemotherapyinduced nausea and vomiting. Community Oncology. 2007;4(4 Supp):3S-11.

6. Boccia RV. Chemotherapy induced Nausea and Vomiting: Identifying and Addressing the Unmet Needs. Journal of Clinical Outcomes Management. 2013;20(8):374-84.

7. Daum BB, Deuson RR, Mavros P, Hansen M, Herrstedt J. Delayed Nausea and Vomiting continue to reduce patient's quality of life after highly and moderate emetogenic chemotherapy despite antiemetic treatment. Journal of Clinical Oncology. 2006;24(27):4472-8. https://doi.org/10.1200/ JCO.2006.05.6382; PMid:16983116.

8. Choi C, Kim B, Kim M, Park J, Yoon A, Kim H, et al. Safety and efficacy of aprepitant, ramosetron, and dexamethasone for chemotherapy-induced nausea and vomiting in patients with ovarian cancer treated with paclitaxel/ carboplatin. Gynecologic Oncology. 2013;e1-e169.

9. Ho CL, Su WC, Hsieh RK, Lin ZZ, Chao TY. A randomized, double-blind, parallel, comparative study to evaluate the efficacy and safety of ramosetron plus dexamethasone injection for the prevention of acute chemotherapyinduced nausea and vomiting. Japanese journal of clinical oncology. 2010;40(4):294-301. https://doi.org/10.1093/jjco/hyp169 ; PMid:20026457.

10. Grunberg S, Chua D, Maru A, Dinis J, DeVandry S, Boice JA, et al. SingleDose Fosaprepitant for the Prevention of Chemotherapy-Induced Nausea and Vomiting Associated With Cisplatin Therapy: Randomized, Double-Blind Study Protocol. Journal of Clinical Oncology. 2011;29(11):1495-501. https:// doi.org/10.1200/JCO.2010.31.7859; PMid:21383291.

11. Grunberg SM, Dugan M, Muss H, Wood M, Burdette-Radoux S, Weisberg T, et al. Effectiveness of a single-day three-drug regimen of dexamethasone, palonosetron, and aprepitant for the prevention of acute and delayed nausea and vomiting caused by moderately emetogenic chemotherapy. Support Care Cancer. 2009;17(5):589-94. https://doi.org/10.1007/s00520-008-05359 ; PMid:19037667.

12. Lordick F, Ehlken B, Ihbe-Heffinger A, Berger K, Krobot KJ, Pellissier J, et al. Health outcomes and cost-effectiveness of aprepitant in outpatients receiving antiemetic prophylaxis for highly emetogenic chemotherapy in Germany. European Journal Of Cancer .2007;43(2):299-307. https://doi. org/10.1016/j.ejca.2006.09.019; PMid:17134890. 